\title{
Surface hydrophobization of bacterial and vegetable cellulose fibers using ionic liquids as solvent media and catalysts
}

\author{
Liliana C. Tomé, ${ }^{a, b}$ Mara G. Freire, ${ }^{a, b}$ Luís Paulo N. Rebelo, ${ }^{b}$ Armando J. D. Silvestre, ${ }^{a}$ \\ Carlos Pascoal Neto, ${ }^{a}$ Isabel M. Marrucho ${ }^{a, b}$ and Carmen S. R. Freire*a
}

Received 19th April 2011, Accepted 2nd June 2011

DOI: $10.1039 / \mathrm{c1gc15432j}$

\begin{abstract}
The surface hydrophobization through heterogeneous chemical modification of bacterial (and vegetable) cellulose fibers with several anhydrides (acetic, butyric, hexanoic and alkenyl succinic anhydrides) and hexanoyl chloride suspended in an ionic liquid, tetradecyltrihexylphosphonium bis(trifluoromethylsulfonyl)imide, [TDTHP][ $\left.\mathrm{NTf}_{2}\right]$, was studied. Furthermore, in the reaction with hexanoyl chloride, another ionic liquid, $N$-hexyl-4-(dimethylamino)pyridinium bis(trifluoromethylsulfonyl)imide, $\left[\mathrm{C}_{6} \mathrm{~N}\left(\mathrm{CH}_{3}\right)_{2}\right.$ py][ $\left.\mathrm{NTf}_{2}\right]$, was used instead of common organic bases as catalyst and to trap the released $\mathrm{HCl}$. The analysis of the ensuing modified fibers by FTIR, XRD and SEM clearly showed that the esterification reactions occurred essentially at the fibers' outmost layers, not affecting their ultrastructure. The degree of substitution (DS) of the ensuing esterified fibers ranged from less than 0.002 to 0.41 ; and in all instances, the fibers' surface acquired a high hydrophobicity. This novel approach constitutes an important strategy in the preparation of modified fibers under greener conditions relaying in the use of non-volatile solvents.
\end{abstract}

\section{Introduction}

Cellulose, the major component of plant cell walls, is undoubtedly the most abundant natural polymer. Its remarkable properties (as well as those of its derivatives), have been exploited by mankind for millennia, particularly in paper and textiles, and new potential applications for this ubiquitous renewable resource are being increasingly hunted, ${ }^{1}$ mainly in response to the predicted scarceness of fossil resources, their unsustainable prices and consequently to the increasing interest in the development of biodegradable materials based on renewable resources. ${ }^{2}$

In addition to the "conventional" vegetable cellulose fibers, other forms of cellulose have also attracted the attention of the scientific community in the last few years, in particular bacterial cellulose (BC) and also other nanocellulose substrates (nanofibrillated cellulose and cellulose whiskers). BC is an extracellular polysaccharide, produced by several bacteria of the Gluconacetobacter genus, as a three-dimensional network of nano- and microfibrills with $10-100 \mathrm{~nm}$ in diameter, which possesses unique physical and mechanical properties, such as its high water holding capacity, crystallinity, tensile strength and Young modulus. ${ }^{3}$

${ }^{a}$ CICECO, Departamento de Quimica, Universidade de Aveiro, Campus Universitário de Santiago, 3810-193, Aveiro, Portugal.

E-mail: cfreire@ua.pt; Fax: +351234370 084; Tel: +351 234401405

${ }^{b}$ Instituto de Tecnologia Química e Biológica, Universidade Nova de

Lisboa, Av. República, Apartado 127, 2780-901, Oeiras, Portugal;

Web: www.itqb.unl.pt
Nanocellulose fibers (as well as vegetable fibers) have found application in several domains, ${ }^{46}$ namely as reinforcing elements in composite materials based on polymeric matrices. ${ }^{7-10}$ The major problems faced by researchers in this field are undoubtedly related to the highly polar surface of the cellulose fibers, associated with its $\mathrm{OH}$-rich structure, which entails (i) a very low interfacial compatibility with non-polar matrices like polyolefins (resulting in inadequate mechanical performance of the corresponding composites), (ii) moisture uptake (which results in loss of fiber strength) and (iii) inter-fiber aggregation by hydrogen bonding (leading to poor fiber dispersion in the composite). ${ }^{11}$ Several strategies have been explored to overcome these drawbacks, mostly involving specific surface treatments of the fibers aimed at reducing its polar character, which include both physical and chemical modifications. ${ }^{12}$ However, most of the chemical approaches described for the surface hydrophobization of cellulose fibers involve the use of hazardous nonpolar organic solvents such as toluene and dichloromethane, among others, ${ }^{13-15}$ which represent an important concern when considering the scale-up of these processes.

Ionic liquids (ILs) are low-melting-point salts, and apart from their broad definition as compounds with a unique combination of properties such as negligible volatility, high stability, and easy recyclability, their most attractive feature is their tunability which allows the design of ILs for each specific purpose. ${ }^{16}$ Although ILs are already very popular in cellulose chemistry, most literature is focused on the dissolution/regeneration and homogeneous derivatization of cellulose. ${ }^{17-19}$ For example, Wu 
et al. ${ }^{20}$ reported the homogeneous acetylation of cellulose in 1-allyl-3-methylimidazolium chloride, [amim] $\mathrm{Cl}$, while Abbott et $a l^{21}$ presented its cellulose $O$-acetylation using a zincbased IL. On the other hand, Barthel and Heinze ${ }^{22}$ carried out acylation and carbanylation of cellulose in 1-butyl-3methylimidazolium chloride, $\left[\mathrm{C}_{4} \mathrm{mim}\right] \mathrm{Cl}$, without catalysts, under mild conditions. Moreover, more recently, Liu et al. ${ }^{23}$ showed the efficient succinoylation of cellulose in [amim] $\mathrm{Cl}$ reaction media. However, the heterogeneous chemical modification of cellulose fibers in ILs has never been reported. In this context, the development of new approaches for the surface hydrophobization of cellulose fibers through heterogeneous chemical modification in ILs, thus limiting the reaction to the outmost layers of cellulose fibers, in order to preserve their ultrastructure and consequently their mechanical properties, constitute an important step forward on the increase of the "greenness" of the processes associated with the valorization of this renewable resource. This approach requires the selection/design of ILs that do not dissolve or swell (at least to a considerable extent) cellulose fibers.

In addition, most conventional procedures described for the modification of cellulose with acyl chlorides involve the use of pyridine (or other hazardous bases) to catalyze the reaction and neutralize the $\mathrm{HCl}$ released during the process in order to avoid fiber degradation. The replacement of such hazardous chemicals by a second IL bearing a basic functionality in the side chain is another important contribution to reduce the environmental concerns associated with these processes. The use of a nonvolatile IL instead of pyridine will reduce the loss of the catalyst to the atmosphere allowing its further recyclability.

In the present work, we describe the surface hydrophobization of bacterial cellulose and vegetable cellulose with several anhydrides and an acyl chloride using a non swelling IL as reaction media, namely tetradecyltrihexylphosphonium bis(trifluoromethylsulfonyl)imide [TDTHP][NTf $\left.{ }_{2}\right]$, and another IL as an acid trap, $N$-hexyl-4-(dimethylamino)pyridinium bis(trifluoromethylsulfonyl)imide, $\left[\mathrm{C}_{6} \mathrm{~N}\left(\mathrm{CH}_{3}\right)_{2}\right.$ py $]\left[\mathrm{NTf}_{2}\right]$, which contains a $N, N$-dimethylamine group. The extension of modification, morphology, crystallinity, contact angles with water and thermal stability of the ensuing modified fibers was also assessed.

\section{Experimental}

\section{Materials}

Bacterial cellulose (BC) in the shredded wet form $(95 \%$ of humidity) was supplied by Forschungszentrum für Medizintechnik und Biotechnologie e.V. (Germany). The vegetable cellulose substrate (VC) used in this work was $\alpha$-cellulose obtained from Sigma-Aldrich. VC fibers were vacuum dried at $60{ }^{\circ} \mathrm{C}$, whereas $\mathrm{BC}$ was freeze-dried before use.

Acetic anhydride (99\%), butyric anhydride (97\%) and hexanoyl chloride $(98 \%)$ were purchased from Fluka and hexanoic anhydride (97\%) was supplied by Sigma-Aldrich. A mixture of alkenyl succinic anhydrides (ASA) composed of different chain lengths was gently supplied by a Portuguese pulp mill.

$N$-Hexyl-4-(dimethylamino)pyridinium bis(trifluoromethylsulfonyl)imide $\left(\left[\mathrm{C}_{6} \mathrm{~N}\left(\mathrm{CH}_{3}\right)_{2}\right.\right.$ py][NTf $\left.\left.\mathrm{NT}_{2}\right]\right)$ was supplied by Merck with a mass fraction purity $\geq 98 \%$. The halides content is below $0.1 \mathrm{wt} \%$. The IL was dried under vacuum and con- stant stirring at $80{ }^{\circ} \mathrm{C}$, for at least $48 \mathrm{~h}$ before use, to remove volatile compounds. Tetradecyltrihexylphosphonium bis(trifluoromethylsulfonyl)imide, [TDTHP][NTf 2 , was kindly provided by Cytec Industries Inc. (with a chloride mass fraction content $<10^{-3}$ ). Given the low purity of [TDTHP][NTf ${ }_{2}$ a repetitive washing procedure with ultrapure water and further drying under vacuum $\left(10^{-5} \mathrm{~Pa}\right)$ at $80^{\circ} \mathrm{C}$, and for at least $48 \mathrm{~h}$, was carried out. After this process, the purity of [TDTHP][ $\mathrm{NTf}_{2}$ ] was evaluated by ${ }^{31} \mathrm{P},{ }^{1} \mathrm{H},{ }^{13} \mathrm{C}$ and ${ }^{19} \mathrm{~F}$ NMR spectra displaying purity mass fractions of $>99 \%$. The water content after the drying procedure was less than $3 \times 10^{-4}$ in mass fraction as measured by Karl-Fischer titration.

All other reagents were analytical grade and used as received.

\section{Cellulose fibers modification}

The methodology used in this work to esterify the BC and VC cellulose fibers with the acyl anhydrides was adapted from established procedures that make use of conventional solvents: ${ }^{13,24}$ one equivalent (relative to the total cellulose $\mathrm{OH}$ functional groups) of the carboxylic acid anhydride was placed in a $25 \mathrm{~mL}$ round-bottom flask, to which dry [TDTHP][NTf ${ }_{2}$ ] ( $5 \mathrm{~mL} \mathrm{~g}^{-1}$ cellulose), $1.8 \mathrm{wt} \%$ of $\mathrm{H}_{2} \mathrm{SO}_{4}$ as catalyst, and finally $\mathrm{BC}$ or $\mathrm{VC}(2 \mathrm{~g})$ were added under magnetic stirring. The reactions were then conducted at $30{ }^{\circ} \mathrm{C}$ for $6 \mathrm{~h}$ (acetic anhydride), 4 days (butyric anhydride) and 11 days (hexanoic anhydride). The esterification of cellulose fibers with ASA was carried out in the same way, but $1.8 \mathrm{wt} \%$ of acetic acid was used as a catalyst and the treatment was conducted at $80^{\circ} \mathrm{C}$ for 15 days.

The establishment of the new approach for the modification of $\mathrm{BC}$ and $\mathrm{VC}$ fibers with hexanoyl chloride was based on the well known cellulose/fatty acyl chloride/pyridine system; ${ }^{15}$ although, in this study, the solvent was replaced by [TDTHP][ $\mathrm{NTf}_{2}$ ] while pyridine was substituted by $\left[\mathrm{C}_{6} \mathrm{~N}\left(\mathrm{CH}_{3}\right)_{2}\right.$ py][NTf $\left.\mathrm{N}_{2}\right]$ : one equivalent (relative to the total $\mathrm{OH}$ groups of cellulose) of hexanoyl chloride was placed in a $25 \mathrm{~mL}$ round-bottom flask and then, dried [TDTHP][NTf 2$]\left(5 \mathrm{~mL} \mathrm{~g}^{-1}\right.$ cellulose) and $\left[\mathrm{C}_{6} \mathrm{~N}\left(\mathrm{CH}_{3}\right)_{2}\right.$ py $]\left[\mathrm{NTf}_{2}\right]$ (1 eq.), and finally $\mathrm{BC}$ or VC fibers $(2 \mathrm{~g})$ were added under a nitrogen atmosphere. The reaction was conducted under magnetic stirring at $80^{\circ} \mathrm{C}$ for $24 \mathrm{~h}$.

At the end of all reactions, the esterified cellulose fibers were filtered and washed with acetone, ethanol, water, and again with ethanol. To remove residual traces of anhydrides or fatty acyl chloride and other impurities, the modified fibers were soxhlet extracted with ethanol for $12 \mathrm{~h}$ and finally dried at $60^{\circ} \mathrm{C}$ for $24 \mathrm{~h}$.

\section{Recovery and purification of the ILs}

The ILs used in the reactions and the first acetone fraction used to wash the esterified cellulose fibers after the reaction were collected and the acetone removed by vacuum evaporation. The IL residue was then washed several times with ultrapure water under magnetic stirring and finally dried under vacuum.

\section{Characterization of the modified cellulose fibers}

FTIR spectra were taken with a Brücker IFS 55 FTIR spectrometer equipped with a single horizontal Golden Gate ATR cell: the resolution was $8 \mathrm{~cm}^{-1}$ after 128 scans. Spectra were collected from 4000 to $500 \mathrm{~cm}^{-1}$. 
The degree of substitution (DS) of all esterified cellulose fibers was determined by alkaline hydrolysis followed by titration as described elsewhere. ${ }^{25}$

X-Ray diffraction (XRD) patterns were measured with a Phillips X'pert MPD diffractometer using $\mathrm{Cu}-\mathrm{K} \alpha$ radiation. XRD measurements were performed with a step width of 0.04 and a time per step of $1 \mathrm{~min}$. The scattered radiation was detected in the angular range from $5^{\circ}$ to $40^{\circ}(2 \theta)$.

Scanning electron microscopy (SEM) micrographs of the unmodified and modified cellulose fibers were obtained using a SU-70 instrument. Samples were coated with evaporated carbon.

The thermogravimetric (TGA) assays were carried out with a Shimadzu TGA-50 analyzer equipped with a platinum cell. Samples were heated at a constant rate of $10{ }^{\circ} \mathrm{C} \mathrm{min}^{-1}$ from room temperature to $800{ }^{\circ} \mathrm{C}$, under a nitrogen flow of

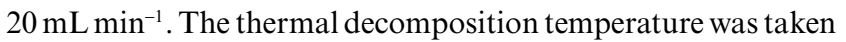
as the onset of significant $(\geq 0.5 \%)$ weight loss, after the initial moisture loss.

Static contact angles $(\theta)$ with water were performed at room temperature using a "surface energy evaluation system" coupled with a video camera and image analyses software commercialized by Brno University (Czech Republic). Each reported value was the average of five independent determinations acquired five seconds after drop $(10 \mu \mathrm{L})$ deposition to ensure the attainment of equilibrium.

\section{Results and discussion}

Bacterial cellulose (BC) and vegetable cellulose (VC) fibers, were modified with several anhydrides with different aliphatic chain lengths (acetic, butyric and hexanoic anhydrides), and an acyl succinic anhydrides mixture (ASA), and one acyl chloride (hexanoyl chloride), in an IL solvent medium, specifically [TDTHP][NTf $\left.{ }_{2}\right]$. This IL solvent was selected from a set of different hydrophobic ILs that do not dissolve or swell (at least in a measurable extent) cellulose fibers, and therefore allows heterogeneous modification limiting the reaction to the outmost layers of cellulose fibers and preserving their ultrastructure and mechanical properties. In addition, the reaction with hexanoyl chloride, was carried out both in absence or in presence of $\left[\mathrm{C}_{6} \mathrm{~N}\left(\mathrm{CH}_{3}\right)_{2}\right.$ py] $\left[\mathrm{NTf}_{2}\right]$ instead of pyridine to catalyze the reaction and to neutralize the $\mathrm{HCl}$ formed during the process. As expected, without catalyst the acylation did not take place, whereas, in its presence, acylation occurred as previously reported in common solvents. ${ }^{14-15,26}$ Table 1 identifies all samples prepared in this study. The DS values of the BC and VC samples modified in the above referred conditions ranged from $0.02-$ 0.24 which is in good agreement with the values obtained for the surface acylation of VC fibers in conventional solvents. ${ }^{24-25}$

\section{FTIR-ATR spectroscopy}

The success of the modification reactions of cellulose fibers with the different esterifying reagents was clearly confirmed and followed by FTIR spectroscopy analysis (Fig. 1).

The confirmation of the occurrence of surface esterification of cellulose fibers with the anhydrides and the hexanoyl chloride was based on the appearance of a new band at around $1730 \mathrm{~cm}^{-1}$ typically attributed the $\mathrm{C}=\mathrm{O}$ vibration of the ester groups. The decrease of the intensity of the band associated with the vibration of the $\mathrm{OH}$ groups at $3300 \mathrm{~cm}^{-1}$ and the increase of the bands, at $2970 \mathrm{~cm}^{-1}$, arising from the vibrations of the $\mathrm{C}_{-}$ $\mathrm{H}$ groups are additional indications of the occurrence of the esterification reactions. The variation of the intensity of the band at $1730 \mathrm{~cm}^{-1}$ is also useful to evaluate the extent of the modification reaction and we found that this parameter was in good agreement with the DS values determined by titration (Table 1).

For the modification with different anhydrides, the reaction time increases considerably with the aliphatic chain length of the substituents due to the well known decrease of the reactivity of carboxylic acid derivatives with the size of the aliphatic chain (Table 1). For the same aliphatic chain length (6 atoms), the acyl chloride is much more reactive than the anhydride counterpart. Moreover, the reaction times, for both anhydrides and hexanoyl chloride, in [TDTHP] $\left[\mathrm{NTf}_{2}\right]$ solvent system are in general higher than those reported for the same reaction in conventional organic solvents, certainly due to the higher viscosity of $[\mathrm{TDTHP}]\left[\mathrm{NTf}_{2}\right] .{ }^{27}$ For example, the modification

Table 1 Identification of the modified BC and VC fibers prepared in [TDTHP][ $\left.\mathrm{NTf}_{2}\right]$ media

\begin{tabular}{|c|c|c|c|c|}
\hline Sample & Cellulose substrate & Modification & Reaction time & DS \\
\hline $\mathrm{BC}$ & \multirow{7}{*}{ Bacterial cellulose } & - & - & - \\
\hline $\mathrm{BC} \mathrm{Ac}$ & & Acetic anhydride & $6 \mathrm{~h}$ & 0.17 \\
\hline BC But & & Butyric anhydride & 4 days & 0.24 \\
\hline BC Hex & & Hexanoic anhydride & 11 days & 0.13 \\
\hline BC ASA & & Alkenyl succinic anhydrides & 15 days & 0.04 \\
\hline $\mathrm{BC} \mathrm{HexCl}^{a}$ & & Hexanoyl chloride & $24 \mathrm{~h}$ & 0.17 \\
\hline $\mathrm{BC} \mathrm{HexCl}^{b}$ & & Hexanoyl chloride & $24 \mathrm{~h}$ & - \\
\hline $\mathrm{VC}$ & \multirow{7}{*}{ Vegetable cellulose } & - & - & - \\
\hline $\mathrm{VC} \mathrm{Ac}$ & & Acetic anhydride & $6 \mathrm{~h}$ & 0.10 \\
\hline VC But & & Butyric anhydride & 4 days & 0.22 \\
\hline VC Hex & & Hexanoic anhydride & 11 days & 0.12 \\
\hline VC ASA & & Alkenyl succinic anhydrides & 15 days & 0.06 \\
\hline $\mathrm{VC} \mathrm{HexCl}{ }^{a}$ & & Hexanoyl chloride & $24 \mathrm{~h}$ & 0.02 \\
\hline $\mathrm{VCHexCl}^{b}$ & & Hexanoyl chloride & $24 \mathrm{~h}$ & - \\
\hline
\end{tabular}




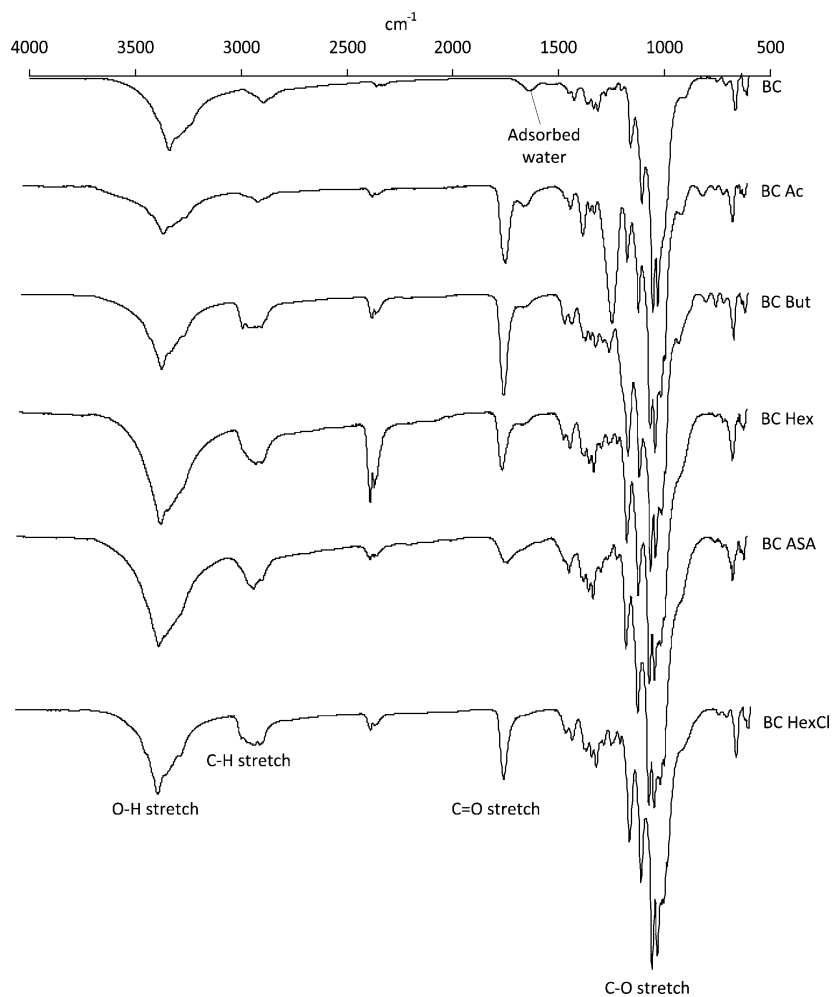

Fig. 1 FTIR-ATR spectra of BC before and after esterification with different anhydrides and hexanoyl chloride.

of cellulose fibers with hexanoyl chloride requires normally $1-$ $6 \mathrm{~h}$ in toluene, ${ }^{15}$ while in the proposed system it takes around $24 \mathrm{~h}$ using comparable reaction temperatures. However, similar reaction times were observed for modification with ASA in both this IL and THF. ${ }^{13}$

In sum, the performance and behavior of the modification reagents (anhydrides and acyl chlorides) in [TDTHP] $\left[\mathrm{NTf}_{2}\right]$ are quite similar to those observed in conventional and volatile organic solvents with exception of the reaction time. However, this parameter could also be improved by using a less viscous IL, like $\left[\mathrm{C}_{4} \mathrm{mim}\right]\left[\mathrm{NTf}_{2}\right] .{ }^{28}$ In fact, some extra experiments (not presented here) carried out using $\left[\mathrm{C}_{4} \mathrm{mim}\right]\left[\mathrm{NTf}_{2}\right]$ as solvent showed that the acylation reaction times could be reduced to about $50 \%$ for similar reaction temperatures and DS values. Nevertheless, we have chosen [TDTHP][NTf ${ }_{2}$ ] as solvent for surface hydrophobization of cellulose because this IL is thermally more stable and less soluble in water, readily available in bulk quantities and less expensive compared to $\left[\mathrm{C}_{4} \mathrm{mim}\right]\left[\mathrm{NTf}_{2}\right]^{29-30}$ Furthermore, all the reaction parameters (IL properties, time, temperature, etc.) could be optimized in order to achieve a desired extent of surface modification for each esterification reagent or cellulose substrate, depending of the envisaged application.

\section{X-Ray diffraction}

$\mathrm{X}$-Ray diffraction is an useful technique for the investigation of the crystalline structure of materials. In this study, X-ray diffraction was used to evaluate the effect of the heterogeneous esterification in [TDTHP] $\left[\mathrm{NTf}_{2}\right]$ on the topochemistry of the BC and VC fibers.
Both unmodified BC and VC fibers displayed the typical $\mathrm{X}$-ray diffraction pattern of native cellulose, cellulose I, with the main diffraction peaks at $2 \theta 14.9,16.3,22.5$, and 34.6 , attributed to the diffraction planes $101,10 \overline{\mathbf{1}}, 002$, and 040 , respectively. All esterified cellulose fibers prepared in this study maintained this diffraction profile, as shown in Fig. 2 and 3, confirming that the modification reactions involved essentially the $\mathrm{OH}$ groups at the surface and the amorphous regions not affecting in a great extent the ultrastructure of $\mathrm{BC}$ and VC fibers.

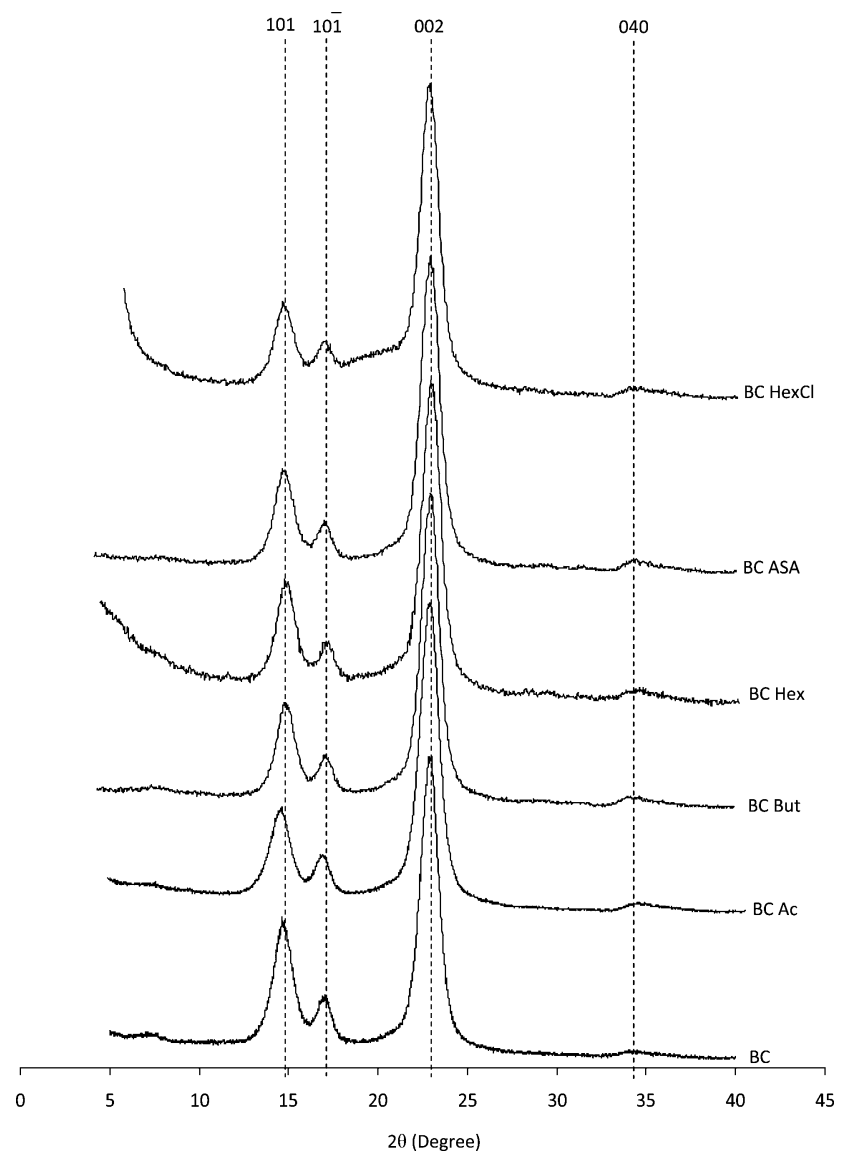

Fig. 2 X-Ray diffractograms of $\mathrm{BC}$ before and after esterification with different anhydrides and hexanoyl chloride.

These results are a first proof that ILs could be used as green solvent systems for the surface hydrophobization of different cellulose fibers with several reagents, including anhydrides and acyl chlorides. Moreover, these results also confirmed the feasibility of using an IL $\left(\left[\mathrm{C}_{6} \mathrm{~N}\left(\mathrm{CH}_{3}\right)_{2}\right.\right.$ py] $\left.\left[\mathrm{NTf}_{2}\right]\right)$ to substitute pyridine (or other hazardous amines) in modification reactions with acyl chlorides.

\section{Morphology}

The effect of the esterification, with anhydrides and acyl chlorides, in [TDTHP] $\left[\mathrm{NTf}_{2}\right]$ on the morphology of BC and VC fibers was evaluated by SEM. As observed in Fig. 4, in general, both cellulose substrates kept their main morphologic features, namely the tridimensional network of nanofibrills and the fibrillar structure, respectively, after modification in IL media, confirming that reactions occurred essentially at the fibers surface not affecting their ultrastructure. Therefore, the 


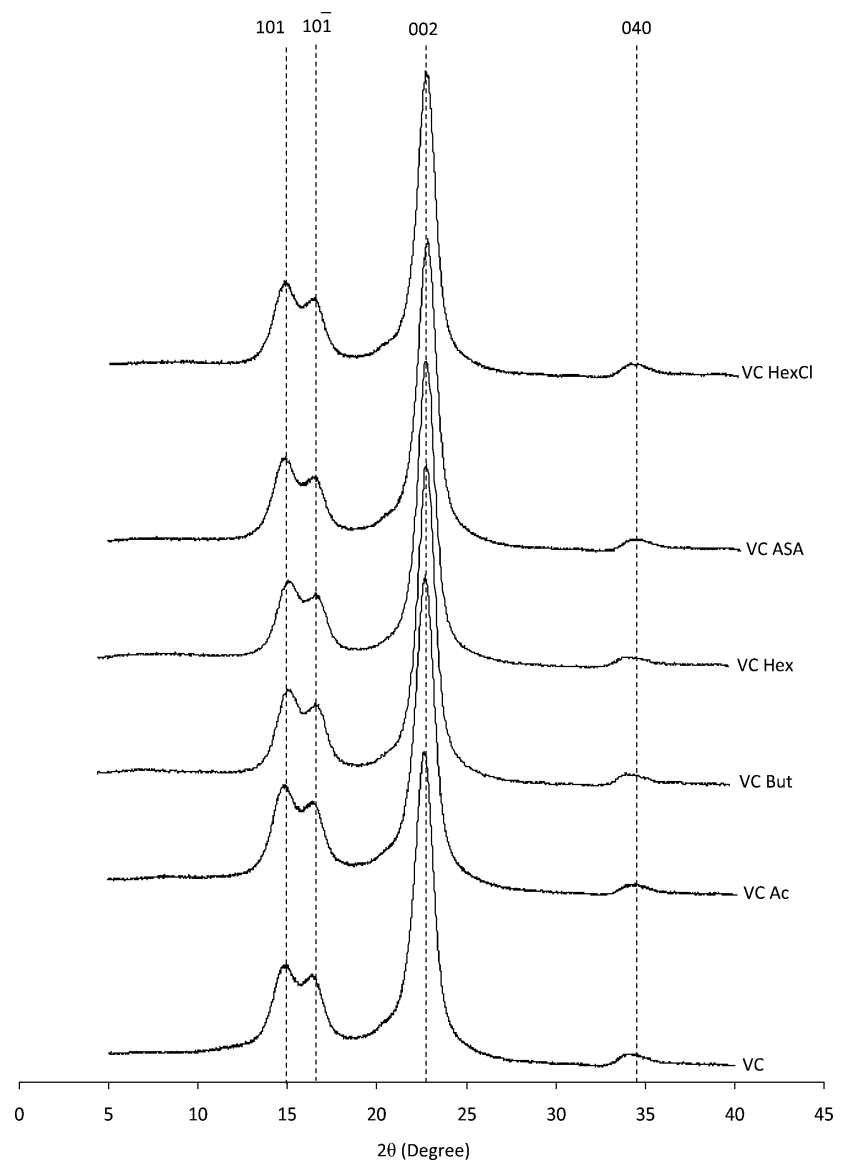

Fig. 3 X-Ray diffractograms of VC before and after esterification with different anhydrides and hexanoyl chloride.

SEM analysis is in good agreement with the reported DS values (Table 1) as well as with the XRD results (Fig. 2 and 3).

\section{Thermal degradation (TGA)}

The TGA tracings of both unmodified BC and VC fibers follow a single weight-loss step with a maximum decomposition temperature at about 349 and $368{ }^{\circ} \mathrm{C}$, respectively (Table 2). In general, all $\mathrm{BC}$ and $\mathrm{VC}$ esterified fibers, modified with the distinct acyl anhydrides and hexanoyl chloride, also displayed this TGA tracing, but are less stable as they started to decompose at considerably lower temperatures than the starting materials (Table 2 and Fig. 5). In addition, the maximum decomposition peak was also slightly shifted to lower temperatures (Table 2). This behavior is normally attributed to the small decrease of crystallinity observed after esterification, ${ }^{31}$ but could also be associated to the high lability of the ester linkages introduced in the cellulose structure. These trends have already been observed for cellulose fibers esterified in conventional solvent systems. ${ }^{14-15}$ For the investigated anhydrides and DS values obtained, the thermal degradation of the $\mathrm{BC}$ and VC fibers was poorly influenced by acyl chain length and DS.

In addition, the TGA also confirmed the enhancement of the hydrophobic character of the $\mathrm{BC}$ and $\mathrm{VC}$ fibers after esterification through the decrease of the loss of weight at $100{ }^{\circ} \mathrm{C}$ attribute to the adsorbed water evaporation.
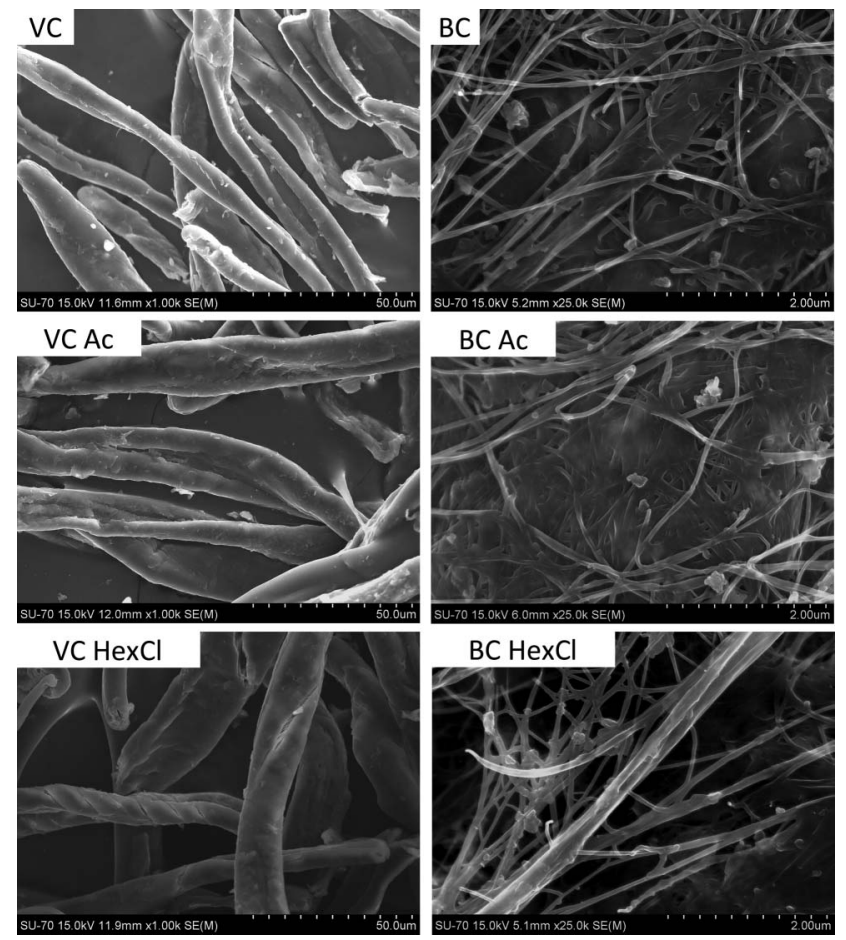

Fig. 4 SEM micrographs of VC and BC before and after esterification with acetic anhydride and hexanoyl chloride.

Table 2 Thermal data for the BC and VC samples, before and after esterification with different acyl anhydrides and hexanoyl chloride, as obtained from the TGA plots

\begin{tabular}{llll}
\hline Sample & $\begin{array}{l}\text { Weight loss } \\
\text { at } 100^{\circ} \mathrm{C}(\%)\end{array}$ & $T_{i}\left({ }^{\circ} \mathrm{C}\right)$ & $T d_{l}\left({ }^{\circ} \mathrm{C}\right)$ \\
\hline BC & 2.80 & 293 & $349(51)^{a}$ \\
BC Ac & 1.77 & 245 & $347(55)$ \\
BC But & 1.70 & 255 & $340(41)$ \\
BC Hex & 2.32 & 256 & $341(44)$ \\
BC ASA & 1.45 & 289 & $346(38)$ \\
BC HexCl & 0,10 & 261 & $339(53)$ \\
VC & 1.97 & 324 & $368(50)$ \\
VC Ac & 0.92 & 263 & $366(56)$ \\
VC But & 1.43 & 282 & $355(53)$ \\
VC Hex & 1.29 & 258 & $358(57)$ \\
VC ASA & 0.98 & 322 & $360(56)$ \\
VC HexCl & 1.48 & 280 & $341(51)$
\end{tabular}

${ }^{a}$ Number in parenthesis refer to the percentage of decomposition attained at $T d_{1}$.

\section{Contact angles}

As previously referred, the main objective of the attachment of long chain aliphatic moieties onto the surface of cellulose fibers is the decrease of their hydrophilicity and therefore of their wettability with polar liquids like water, aiming to tailor their hydrophobic surface character. The measurement of the contact angles $\left(\theta /{ }^{\circ}\right)$ formed by a liquid onto a solid surface is a common technique used to asses the effect of chemical (or physical) treatments on the surface properties of materials, including cellulose and other polysaccharides, since it is a quantitative measurement of the wetting behavior of a solid by a liquid. ${ }^{32}$ 


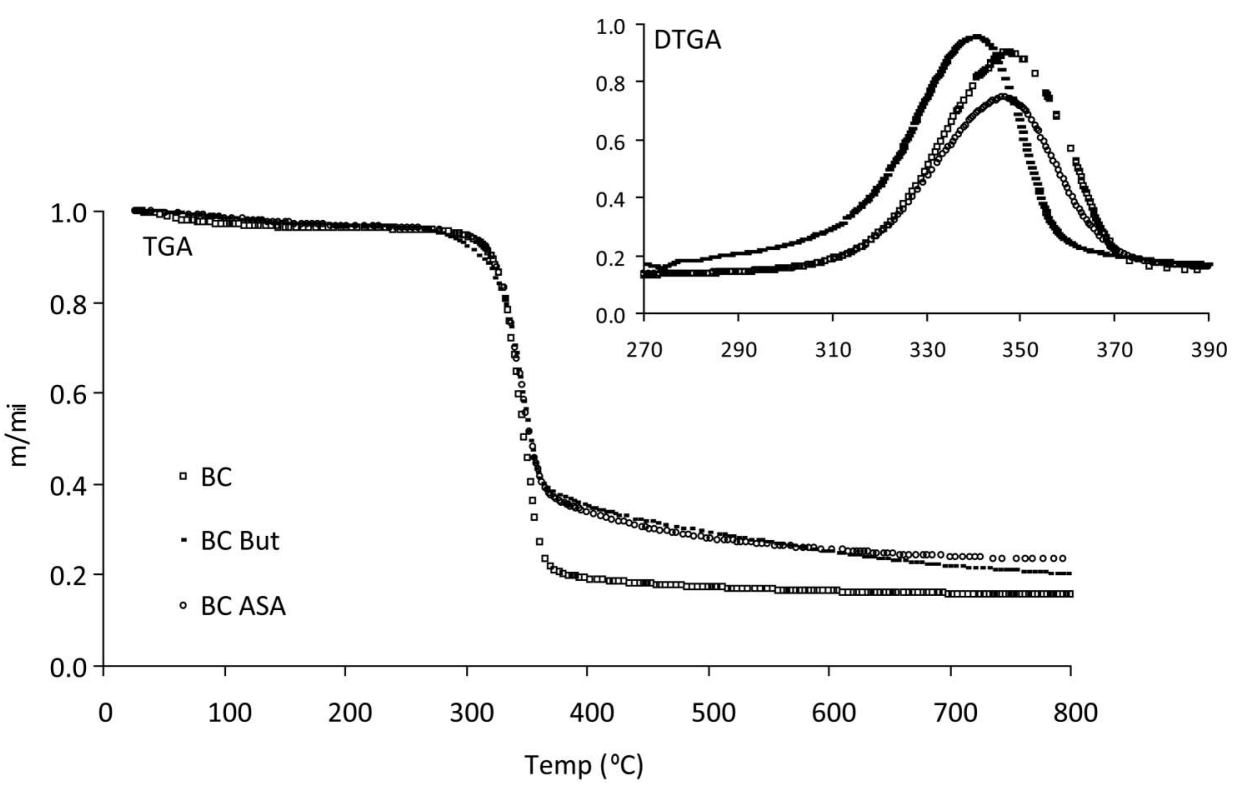

Fig. 5 Thermogravimetric curves for BC before and after esterification with butyric anhydride and alkenyl succinic anhydride.

As shown in Fig. 6, the contact angles with water increased considerably after the esterification reactions with all anhydrides and hexanoyl chloride confirming the success of the surface hydrophobization of cellulose fibers in IL solvent systems with these reagents. No significant differences were observed between the $\mathrm{BC}$ or VC modified fibers prepared with the distinct anhydrides and hexanoyl chloride. In fact, a high hydrophobicity was attained even for very low DS values, as in the case of the fibers modification with ASA.

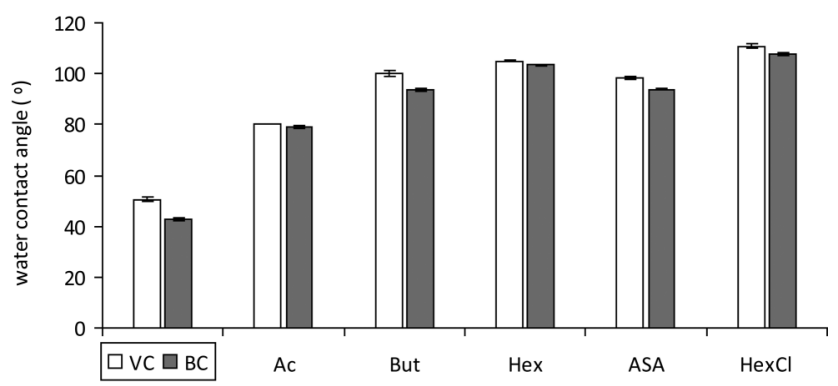

Fig. 6 Contact angles $\left(\theta /{ }^{\circ}\right)$ on $\mathrm{BC}$ and $\mathrm{VC}$ with water before and after esterification with different anhydrides and hexanoyl chloride.

\section{Recovery and purification of the IL}

From an economic and environmental point of view, it is crucial to recover and recycle ILs after the derivatization reactions. In this study, the recovery and recycling of [TDTHP] $\left[\mathrm{NTf}_{2}\right]$ after the heterogeneous esterification reactions with the anhydrides and with hexanoyl chloride was pursued.

The purity of the recycled [TDTHP][NTf 2 , recovered and purified after the esterification of the cellulose fibers with anhydrides, was above $99 \%$, as confirmed by ${ }^{31} \mathrm{P},{ }^{1} \mathrm{H},{ }^{13} \mathrm{C}$ and ${ }^{19} \mathrm{~F}$ NMR spectroscopy. The recycled [TDTHP][NTf $\left.{ }_{2}\right]$ were then reused, in the same reaction conditions, and showed a similar behavior and performance as the IL initially used. However, the recycled [TDTHP][NTf ${ }_{2}$, used on cellulose esterification with hexanoyl chloride, presented a lower degree of purity than the previous systems, after the same repetitive washing procedure, because it contained always $\left[\mathrm{C}_{6} \mathrm{~N}\left(\mathrm{CH}_{3}\right)_{2}\right.$ py] $\left[\mathrm{NTf}_{2}\right]$ used in these reaction. Nevertheless, this situation does not constitute a relevant problem because the ILs mixture was successfully reused as reaction media in the acylation of cellulose with hexanoyl chloride.

\section{Conclusions}

The surface hydrophobization of cellulosic substrates, with different acyl anhydrides and hexanoyl chloride, was successfully attained using [TDTHP][ $\mathrm{NTf}_{2}$ ] as solvent media. Furthermore, the effectiveness of $\left[\mathrm{C}_{6} \mathrm{~N}\left(\mathrm{CH}_{3}\right)_{2}\right.$ py][NTf $]$ as catalyst in the esterification of cellulose acyl chlorides was clearly demonstrated. The modified cellulose fibers were characterized in terms of extent of modification, crystallinity, morphology, thermal stability and surface wettability. Overall, the performance of the surface modification reactions with the acyl anhydrides and chlorides in this IL is quite similar with that observed in conventional organic solvents, excepting for the reaction time that was in general higher.

This approach opens new opportunities for the development of reinforcement elements for green high-tech composites making use of ionic liquids as efficient non-volatile solvents.

\section{Acknowledgements}

FCT (Fundação para a Ciência e Tecnologia) is acknowledged for Liliana $\mathrm{C}$. Tomé $(\mathrm{PhD}$ research grant SFRH/BD/72830/2010) and Mara G. Freire (Postdoctoral research grant SFRH/BPD/41781/2007), and for financial support through the Projects PTDC/QUI/68472/2006 and PTDC/QUI/72903/2006. The authors also acknowledge Cytec Industries for kindly providing [TDTHP] $\left[\mathrm{NTf}_{2}\right]$ used in this work. 


\section{References}

1 D. Klemm, B. Heublein, H.-P. Fink and A. Bohn, Angew. Chem., Int. Ed., 2005, 44, 3358-3393.

2 M. N. Belgacem and A. Gandini, Monomers, Polymers and Composites from Renewable Resources Elsevier, Amsterdam 2008.

3 E. Pecoraro, D. Manzani, Y. Messaddeq and S. J. L. Ribeiro, in Monomers Polymers and Composites from Renewable Resources, ed. M. N. Belgacem and A. Gandini, Elsevier, Amsterdam, 2008.

4 T. Heinze and K. Petzold, in Monomers, Polymers and Composites from Renewable Resources, ed. M. N. Belgacem and A. Gandini, Elsevier, Amsterdam, 2008.

5 C. Aulin, J. Netrval, L. Wagberg and T. Lindstrom, Soft Matter, 2010, 6, 3298-3305.

6 M. Zaborowska, A. Bodin, H. Bäckdahl, J. Popp, A. Goldstein and P. Gatenholm, Acta Biomater., 2010, 6, 2540-2547.

7 L. C. Tomé, R. J. B. Pinto, E. Trovatti, C. S. R. Freire, A. J. D. Silvestre, C. P. Neto and A. Gandini, Green Chem., 2011, 13, 419-427.

8 S. C. M. Fernandes, C. S. R. Freire, A. J. D. Silvestre, C. P. Neto, A. Gandini, L. A. Berglund and L. Salmén, Carbohydr. Polym., 2010, 81, 394-401.

9 C. Eyholzer, F. Lopez-Suevos, P. Tingaut, T. Zimmermann and K. Oksman, Cellulose, 2010, 17, 793-802.

10 E. Trovatti, L. Oliveira, C. S. R. Freire, A. J. D. Silvestre, C. P. Neto, J. J. C. C. Pinto and A. Gandini, Compos. Sci. Technol., 2010, 70, $1148-1153$.

11 A. Dufresne, in Monomers, Polymers and Composites from Renewable Resources, ed. M. N. Belgacem and A. Gandini, Elsevier, Amsterdam, 2008.

12 M. N. Belgacem and A. Gandini, in Monomers, Polymers and Composites from Renewable Resources, ed. M. N. Belgacem and A. Gandini, Elsevier, Amsterdam, 2008.

13 J.-A. Trejo-O'Reilly, J.-Y. Cavaille and A. Gandini, Cellulose, 1997, 4, 305-320.

14 L. C. Tomé, L. Brandão, A. Mendes, A. J. D. Silvestre, C. P. Neto, A. Gandini, C. S. R. Freire and I. M. Marrucho, Cellulose, 2010, 17, 1203-1211.

15 C. S. R. Freire, A. J. D. Silvestre, C. P. Neto, M. N. Belgacem and A. Gandini, J. Appl. Polym. Sci., 2006, 100, 1093-1102.
16 N. V. Plechkova and K. R. Seddon, Chem. Soc. Rev., 2008, 37, $123-$ 150

17 R. P. Swatloski, S. K. Spear, J. D. Holbrey and R. D. Rogers, J. Am. Chem. Soc., 2002, 124, 4974-4975.

18 T. Heinze, S. Dorn, M. Schöbitz, T. Liebert, S. Köhler and F. Meister, Macromol. Symp., 2008, 262, 8-22.

19 T. Liebert and T. Heinze, BioResources, 2008, 3, 576-601.

20 J. Wu, J. Zhang, H. Zhang, J. He, Q. Ren and M. Guo, Biomacromolecules, 2004, 5, 266-268.

21 A. P. Abbott, T. J. Bell, S. Handa and B. Stoddart, Green Chem., 2005, 7, 705-707.

22 S. Barthel and T. Heinze, Green Chem., 2006, 8, 301-306.

23 C. F. Liu, R. C. Sun, A. P. Zhang, J. L. Ren, X. A. Wang, M. H. Qin, Z. N. Chao and W. Luo, Carbohydr. Res., 2007, 342, 919926.

24 G. Frisoni, M. Baiardo, M. Scandola, D. Lednická, M. C. Cnockaert, J. Mergaert and J. Swings, Biomacromolecules, 2001, 2, 476482.

25 C. S. R. Freire, A. J. D. Silvestre, C. P. Neto and R. M. A. Rocha, Cellulose, 2005, 12, 449-458.

26 L. C. Tomé, C. M. B. Gonçalves, M. Boaventura, L. Brandão, A. M. Mendes, A. J. D. Silvestre, C. P. Neto, A. Gandini, C. S. R. Freire and I. M. Marrucho, Carbohydr. Polym., 2011, 83, 836-842.

27 C. M. S. S. Neves, P. J. Carvalho, M. G. Freire and J. A. P. Coutinho, J. Chem. Thermodyn., 2011, 43, 948-957.

28 M. Tariq, P. J. Carvalho, J. A. P. Coutinho, I. M. Marrucho, J. N. C. Lopes and L. P. N. Rebelo, Fluid Phase Equilib., 2011, 301, 22-32.

29 M. G. Freire, P. J. Carvalho, R. L. Gardas, L. s. M. N. B. F. Santos, I. M. Marrucho and J. A. P. Coutinho, J. Chem. Eng. Data, 2008, 53, $2378-2382$.

30 M. G. Freire, P. J. Carvalho, R. L. Gardas, I. M. Marrucho, L. M. N. B. F. Santos and J. A. P. Coutinho, J. Phys. Chem. B, 2008, 112, 1604-1610.

31 P. Jandura, B. Riedl and B. V. Kokta, Polym. Degrad. Stab., 2000, 70, 387-394.

32 D. Briggs, D. G. Rance and B. J. Briscoe, in Comprehensive Polymer Science: The Synthesis, Characterization, Reactions and Applications of Polymers, ed. C. Booth and C. Price, Pergamon Press, Oxford, 1989, vol. 2, pp. 707-715. 